\title{
No erythropoietin-induced growth is observed in non-small cell lung cancer cells
}

\author{
ARMIN FRILLE ${ }^{1,3,4}$, KATHARINA LEITHNER ${ }^{1}$, ANDREA OLSCHEWSKI ${ }^{2}$, \\ HORST OLSCHEWSKI $^{1}$, CHRISTOPH WOHLKÖNIG ${ }^{1}$ and ANDELKO HRZENJAK ${ }^{1,2}$ \\ ${ }^{1}$ Division of Pulmonology, Department of Internal Medicine, Medical University of Graz, 8036 Graz; \\ ${ }^{2}$ Ludwig Boltzmann Institute for Lung Vascular Research, 8010 Graz, Austria
}

Received August 7, 2017; Accepted November 21, 2017

DOI: $10.3892 /$ ijo.2017.4225

\begin{abstract}
Lung cancer patients have the highest incidence of anemia among patients with solid tumors. The use of recombinant human erythropoietin (Epo) has consistently been shown to reduce the need for blood transfusions and to increase hemoglobin levels in lung cancer patients with chemotherapyinduced anemia. However, clinical and preclinical studies have prompted concerns that Epo and the presence of its receptor, EpoR, in tumor cells may be responsible for adverse effects and, eventually, death. The question has been raised whether Epo promotes tumor growth and inhibits the death of cancer cells. In this study, we investigated the presence and functionality of EpoR, as well as the implications of Epo upon the proliferation and survival of lung cancer cells. Since the protein expression of both Epo and EpoR is induced by hypoxia, which is frequently present in lung cancer, the cells were treated with Epo under both normoxic and hypoxic conditions $\left(1 \% \mathrm{O}_{2}\right)$. By using quantitative (real-time) PCR, western blot analysis, and immunocytochemical staining, three non-small cell lung cancer (NSCLC) cell lines (A427,
\end{abstract}

Correspondence to: Dr Christoph Wohlkönig, Division of Pulmonology, Department of Internal Medicine, Medical University of Graz, Auenbruggerplatz 15, $8036 \mathrm{Graz}$, Austria

E-mail: c.wohlkoenig@medunigraz.at

Present addresses: ${ }^{3}$ Department of Respiratory Medicine, University of Leipzig, 04103 Leipzig; ${ }^{4}$ Integrated Research and Treatment Center (IFB) Adiposity Diseases, University Medical Center Leipzig, 04013 Leipzig, Germany

Abbreviations: Akt, protein kinase B; ANOVA, analysis of variance; Epo, erythropoietin; EpoR, erythropoietin receptor; ERK1/2, extracellular signal-regulated kinases $1 / 2$; Jak2, Janus kinase 2; KRAS gene, Kirsten rat sarcoma gene; MAP kinase, mitogen-activated protein kinase; NSCLC, non-small cell lung cancer; PI3K, phosphatidylinositol-3-kinase; STAT5, signal transducer and activator of transcription 5

Key words: non-small cell lung cancer, chemotherapy-induced anemia, erythropoietin, erythropoietin receptor, proliferation, apoptosis
A549 and NCI-H358) were analyzed for the expression of EpoR and its specific downstream signaling pathways [Janus kinase 2 (Jak2)-signal transducer and activator of transcription 5 (STAT5), phosphatidylinositol-3-kinase (PI3K)-Akt, mitogen-activated protein (MAP) kinase]. The effects of $100 \mathrm{U} / \mathrm{ml}$ Epo on cell proliferation and cisplatin-induced apoptosis were assessed. All NSCLC cell lines expressed EpoR mRNA and protein, while these levels differed considerably between the cell lines. We found the constitutive phosphorylation of EpoR and most of its downstream signaling pathways (STAT5, Akt and ERK1/2) independently of Epo administration. While Epo markedly enhanced the proliferation and reduced apoptosis of Epo-dependent UT-7/Epo leukemia cells, it did not affect tumor cell proliferation or the cisplatininduced apoptosis of NSCLC cells. Thus, this in vitro study suggests that there are no tumor-promoting effects of Epo in the NSCLC cell lines studied, neither under normoxic nor under hypoxic conditions.

\section{Introduction}

Lung cancer is the leading cause of cancer-related mortality among males and the second among females worldwide (1). Platinum-based chemotherapy is still an important cornerstone of most combination regimens applied in lung cancer (2). Lung cancer patients have the highest incidence of anemia among patients with solid tumors (3). Anemia is a major cause of cancer-related fatigue that largely decreases the health-related quality of life (3) and is associated with the decreased survival of lung cancer patients (4). The causes of cancer-related anemia are multifactorial and may be for one attributed to malignancy itself through suppressed hematopoiesis (infiltration of bone marrow and functional iron deficiency), enhanced destruction (hemolysis) and blood loss (5). In addition, myelosuppressive therapy regimens, such as chemotherapy or ionizing radiation may cause considerable anemia in cancer patients. Apart from the correction of nutritional deficiencies and red blood cell transfusion, the use of recombinant human erythropoietin (Epo) has consistently been shown to increase hemoglobin levels and to thus reduce the need for transfusions in lung cancer patients with chemotherapy-related anemia $(3,6,7)$.

In hematopoietic progenitor cells, Epo binds to its cytokine receptor, EpoR, that forms a homodimer and leads to 
conformational changes in the proximal cytoplasmic tail of EpoR. Since EpoR has no intrinsic tyrosine kinase activity to initiate receptor-mediated signaling, receptor phosphorylation and thus activation is usually mediated by the adapter protein Janus kinase 2 (Jak2). Conformational changes of the cytoplasmic tail of EpoR homodimer after the binding of Epo leads to the autophosphorylation of Jak2 and the transphosphorylation of cytoplasmic tyrosine residues of EpoR. In turn, this activates four key signal transduction pathways of EpoR (8). In detail, they consist principally of pathways involving signal transducer and activator of transcription 5 (STAT5), mitogenactivated protein (MAP) kinase, phosphatidylinositol 3-kinase $(\mathrm{PI} 3 \mathrm{~K})$ and protein kinase $\mathrm{C}$, whose effects are summarized by the promotion of proliferation and differentiation, and the suppression of apoptosis (8).

However, over the past decade, there has been growing concern from both in vitro and in vivo studies that Epo may promote the growth and survival not only of hematopoietic progenitor cells, but also that of solid tumor cells $(9,10)$. Due to the observed increased mortality in cancer patients, including lung cancer patients (11), who were treated with recombinant human Epo (12), the recommendations of the American Society of Hematology/Clinical Oncology in 2008 (13) and 2010 (7) and the Clinical Practice Guidelines in Oncology of the National Comprehensive Cancer Network on cancerand chemotherapy-induced anemia in 2016 (14) approved the use of recombinant human Epo for patients receiving chemotherapy for palliative intent only. It remains to be determined whether there are direct effects of Epo on tumor cells, which are responsible for the increased mortality.

EpoR mRNA and protein have been identified in several cancer cell lines and in different types of cancer $(9,15)$. In some cell lines, Epo treatment is responsible for a statistically significant growth advantage $(16,17)$, the reduced initiation of apoptosis $(18,19)$, or increased angiogenesis $(20,21)$. Both Epo and its receptor, EpoR, have been shown to be expressed in non-small cell lung cancer (NSCLC) specimens (22). Furthermore, NSCLC cells have been demonstrated to have a functional, Epo-dependent receptor that is able to activate three key Epo-signaling pathways (23). The presence of EpoR, its immunoblot detection, and its effects on cancer cells are still a cause of controversy. Another aspect is hypoxia, which is a common feature of solid tumors (24), a well-known inducer of Epo and EpoR (25) and is also responsible for the induction of resistance to chemotherapy (26). For these reasons, in the present study, we have paid particular attention to the cellular effects of exogenous Epo in an oxygen-reduced atmosphere $\left(1 \% \mathrm{O}_{2}\right.$, referred to as hypoxia).

In the present in vitro study, we investigated the presence and activity of EpoR, as well as its signal transduction pathways, and focused on its effects on the proliferation and survival of three NSCLC cell lines (A427, A549 and NCI-H358). We mimicked the hypoxic tumor microenvironment by performing experiments under hypoxic conditions. As a proof of principle, we utilized a well-established EpoRpositive, Epo-dependent cell line, UT-7/Epo. The findings of this study may enhance our understanding of the expression of EpoR and the cellular effects of Epo on NSCLC cells, particularly in the context of hypoxia. Since safety issues are a matter of recent debate regarding the use of Epo in anemic cancer patients due to its possible direct effects on cancer cells, this study adds important information to this field.

\section{Materials and methods}

Tumor cell lines and culture. The human NSCLC cell lines, A427 and A549, were purchased from Cell Lines Service (Eppelheim, Germany) and cultured in Dulbecco's modified Eagle's medium (DMEM)-F12 culture medium (Gibco, Paisley, UK). The human NSCLC cell line, NCI-H358, was ordered from the American Type Culture Collection (ATCC, Manassas, VA, USA) and cultured in RPMI-1640 culture medium (Roswell Park Memorial Institute medium, ATCC). The Epo-dependent human megakaryoblastic leukemia cell line, UT-7/Epo, which served as a positive control for EpoR (27), was a generous gift from Professor Norio Komatsu (Department of Hematology, Juntendo University, School of Medicine, Tokyo, Japan) and was cultured in Iscove's modified Dulbecco's medium (IMDM; Gibco). They were supplemented with $0.4 \mathrm{U} / \mathrm{ml}$ recombinant hyman Epo (rHuEpo; Epoetin alfa, Erypo 10,000 U/ml; Janssen-Cilag Pharma, Vienna, Austria) every 3-4 days following a medium change, following the protocol described in the study by Erickson-Miller et al (28). The culture media were supplemented with $2 \mathrm{mM}$ L-glutamine (Gibco) if absent, 10\% fetal calf serum (FCS; Biowest, Nuaillé, France), $100 \mathrm{U} / \mathrm{ml}$ penicillin and $100 \mu \mathrm{g} / \mathrm{ml}$ streptomycin (Gibco). All 4 cell lines were cultured in a humidified incubator providing $21 \% \mathrm{O}_{2}$ and $5 \% \mathrm{CO}_{2}$ at $37^{\circ} \mathrm{C}$ referred to as the normoxic or ambient condition.

Hypoxic conditions. The cells were cultured in a humidified incubator at $37^{\circ} \mathrm{C}$ in an atmosphere containing $1 \% \mathrm{O}_{2}$ and $5 \% \mathrm{CO}_{2}$ regulated through a $\mathrm{N}_{2}$ and a $\mathrm{CO}_{2}$ gas mixture (Air Liquide, Paris, France) in the automated Xvivo system G300CL (BioSpherix, Ltd., Lacona, NY, USA), which served as a hypoxic processing chamber. Unless stated otherwise, the cells were pre-incubated for 3 days under hypoxic conditions prior to being used in the experiments.

RNA isolation and quantitative (real-time) PCR. The cells were harvested, centrifuged and the pellets were resuspended in RLT buffer (Qiagen, Hilden, Germany) for cell lysis. Total RNA was extracted using the RNeasy Mini kit (Qiagen) including DNA digestion with RNase-Free DNase Set (Qiagen) according to the manufacturer's instructions. Complementary DNA was synthesized using the Revert-Aid ${ }^{\mathrm{TM}} \mathrm{H}$ Minus First Strand cDNA Synthesis kit (Fermentas GmbH, St. Leon-Rot, Germany). Quantitative PCR was conducted with cDNA from at least 3 independent experiments and carried out in triplicate. The amplification and detection of cDNA was performed using the AB 7900 Detection system (Applied Biosystems, Carlsbad, CA, USA). PCR reaction mix (10 $\mu \mathrm{l})$ contained 5.0 $\mu \mathrm{l}$ TaqMan Gene Expression Master Mix, $0.5 \mu 1$ Assay-on-Demand TaqMan Gene Expression Assay (Applied Biosystems), forward and reverse primer for Epo (Hs00171267_m1), EpoR (Hs00959427_m1), and $\beta$-actin (ACTB, Hs99999903_m1), $0.5 \mu \mathrm{l}$ cDNA and $4.0 \mu \mathrm{l}$ distilled $\mathrm{H}_{2} \mathrm{O}$. The cycling protocol was as follows: One cycle at $50^{\circ} \mathrm{C}$ for $2 \mathrm{~min}$ and $95^{\circ} \mathrm{C}$ for $10 \mathrm{~min}$ followed by 45 cycles consisting of denaturation at $95^{\circ} \mathrm{C}$ for 
$15 \mathrm{sec}$, annealing of primers and elongation at $60^{\circ} \mathrm{C}$ for $1 \mathrm{~min}$. The mRNA results were displayed relative to $\beta$-actin as a reference gene. Calculations were performed using the relative expression software tool REST version 2.0.7 and the comparative $\mathrm{C}_{\mathrm{T}}$ method (29).

Western blot analysis. The cells were harvested and lysed with ice-cold RIPA buffer (Sigma-Aldrich, St. Louis, MO, USA) supplemented with protease inhibitor cocktail (Complete mini; Roche Diagnostics, Indianapolis, IN, USA) and phosphatase inhibitor cocktail (PhosSTOP; Roche Diagnostics). For the analysis of EpoR and its downstream signaling, all cell lines were treated with $100 \mathrm{U} / \mathrm{ml} \mathrm{rHuEpo} \mathrm{in} \mathrm{a} \mathrm{time} \mathrm{course}$ manner $(0,5,15,30$ and $60 \mathrm{~min})$. In detail, $2 \times 10^{5}$ cells/dish were seeded out in $35-\mathrm{mm}$ Petri dishes with $2 \mathrm{ml}$ medium containing $10 \%$ heat-inactivated FCS under normoxic conditions. After $72 \mathrm{~h}$, the cells were subjected to starvation medium containing $0 \% \mathrm{FCS}$ for $24 \mathrm{~h}$. The starvation medium was renewed and after $4 \mathrm{~h}$ the cells were treated with $100 \mathrm{U} / \mathrm{ml}$ rHuEpo and harvested at the time-points indicated above. Protein concentrations were determined using a BCA Protein Assay kit (Merck KGaA, Darmstadt, Germany) according to the manufacturer's instructions. In total, $10-40 \mu \mathrm{g}$ of total protein were separated via $8 \%$ SDS-PAGE and transferred onto nitrocellulose membranes (Bio-Rad Laboratories, Hercules, CA, USA). The membranes were blocked in 5\% milk TBS-T $(20 \mathrm{mM}$ Tris-HCl, $140 \mathrm{mM} \mathrm{NaCl}, 0.1 \%$ Tween$20, \mathrm{pH}$ 7.6) for $1 \mathrm{~h}$ at room temperature, then incubated overnight with primary antibodies diluted in $1 \%$ milk or $5 \%$ bovine serum albumin (BSA). The primary antibodies used were as follows: Rabbit polyclonal antibody against EpoR (1:500; M-20; Sc-697; Santa Cruz Biotechnology Inc., Santa Cruz, CA, USA), rabbit polyclonal antibody against p-EpoR (Tyr456; 1:1,000; Sc-20236-R; Santa Cruz Biotechnology), purified mouse anti-human hypoxia-inducible factor (HIF)-1 $\alpha$ antibody (1:500; clone 54/HIF-1 $\alpha$; BD Biosciences, San Diego, CA, USA), monoclonal antibody against STAT-5 alpha c-term (1:500; AJ1741a; Abgent, Oxfordshire, UK), polyclonal antibody against p-STAT-5a-Y694 (1:500; AP3268a; Abgent), mouse monoclonal antibody against $\beta$-actin (1:2,000; Sc-47778; Santa Cruz Biotechnology), rabbit polyclonal antibody against Akt (1:1,000; \#9272), p-Akt (Ser473; 1:1,000; \#9271S), ERK1/2 (1:1,000; \#9102) and p-ERK1/2 (Thr202/Tyr204; 1:1,000; \#9101S) (all from Cell Signaling Technology, Danvers, MA, USA). The membranes were incubated with specific horseradish peroxidase (HRP)-conjugated secondary antibodies diluted in $1 \%$ milk TBS-T for $1 \mathrm{~h}$ at room temperature. Immunoreactivity was detected using SuperSignal West Pico or Femto Chemiluminescent Substrate (Thermo Fisher Scientific, Rockford, IL, USA) and visualized on a Kodak T-MAX G/RA film (Carestream Health France, Noisy-Le-Grand Cedex, France).

Immunocytochemical staining and confocal microscopy. A total of 150,000 cells per chamber were seeded out in 2-well chamber slides (Nunc, Langenselbold, Germany) and cultured in complete culture medium for $48 \mathrm{~h}$ under hypoxic conditions. Thereafter, the cells were fixed in $4 \%$ formaldehyde containing $2 \%$ sucrose for $10 \mathrm{~min}$ and permeabilized with phosphate-buffered saline (PBS) containing 0.5\% Triton X-100
(Sigma-Aldrich) for $5 \mathrm{~min}$. Antibodies were diluted in PBS containing 1\% BSA solution and applied for $1 \mathrm{~h}$ at room temperature. The primary antibody (EpoR, sc-697; Santa Cruz Biotechnology) was diluted 1:50 and the secondary antibody (Alexa Fluor ${ }^{\circledR}$ 555, A21428; Thermo Fisher Scientific) 1:200. Controls included the omission of the primary antibody for A427 cells, or using an isotype immunoglobulin G (rabbit polyclonal IgG: ab27478; Abcam, Cambridge, UK) as a primary antibody for A549 and NCI-H358 cells. Nuclei were counterstained with a fluorescent mounting medium containing DAPI (Vector Laboratories, Inc., Burlingame, CA, USA). The cells were examined using a Zeiss Axiovert 200M microscope (Carl Zeiss, Oberkochem, Germany) and LSM 510 release version 4.0 software. Images were acquired using a $63 \mathrm{X}$ oil immersion objective with a 1.4 numeric aperture. The optical slice thickness was below $1.4 \mu \mathrm{m}$.

Analysis of cell proliferation and viability. To examine the effects of Epo on cell proliferation, the cells treated with or without Epo treatment under normoxic and hypoxic conditions were counted daily for 3 consecutive days using electronic pulse area analysis (CASY; Innovatis, Reutlingen, Germany). The cells were equally plated in duplicate $\left(2 \times 10^{5}\right.$ cells/dish) in $35-\mathrm{mm}$ Petri dishes. For $24 \mathrm{~h}$, the culture media were totally deprived of FCS, then refreshed, and media containing heatinactivated $10 \%$ FCS, plus rHuEpo $(100 \mathrm{U} / \mathrm{ml})$ were added. To achieve the complete inactivation of endogenous Epo, fetal calf serum (FCS) was incubated for $30 \mathrm{~min}$ at $56^{\circ} \mathrm{C}$ prior to the addition to the cell medium, according to the protocol described in the study by Belenkov et al (30). After $3 \mathrm{~h}$ of cell settlement, the cells were incubated under normoxic or hypoxic conditions. An additional group of UT-7/Epo cells was administered $0.4 \mathrm{U} / \mathrm{ml}$ Epo for basal stimulation. At 24, 48 and $72 \mathrm{~h}$, the cell supernatant was collected, and the adherent cells were harvested by trypsinization. Cell number and cell viability were determined using CASY.

Determination of cell apoptosis. To determine apoptosis by the detection of activated caspase-3, the NSCLC and UT-7/Epo cells were pre-incubated under normoxic conditions for $48 \mathrm{~h}$ in their starvation media containing $1 \%$ FCS and $\mathrm{rHuEpo}(100 \mathrm{U} / \mathrm{ml})$, while the control group received no Epo. An additional group of UT-7/Epo cells received basal stimulation of $0.4 \mathrm{U} / \mathrm{ml}$ Epo. The cells were split into $5 \times 10^{5}$ cells per culture flask with Epo-containing medium (0.4 or $100 \mathrm{U} / \mathrm{ml})$. Cisplatin $(8 \mu \mathrm{M} ; 1 \mathrm{mM}$ stock in $0.9 \% \mathrm{NaCl}$; Central Pharmacy of the University Hospital, Medical University of Graz, Graz, Austria) was added after $3 \mathrm{~h}$ of cell settlement. This relatively low cisplatin concentration was used in order to avoid too potent and rapid apoptotic effects induced by higher cisplatin concentrations, particularly in the UT-7/Epo cell line $(31,32)$. After $48 \mathrm{~h}$, the cells were brought into suspension by trypsinization, collected and stained with the Caspase-3 Intracellular Activity Assay kit I (PhiPhiLux ${ }^{\circledR}$ G1D2; Merck, Darmstadt, Germany). Therefore, $5 \times 10^{5}$ cells were centrifuged, resuspended with $25 \mu 1$ of PhiPhiLux substrate and $25 \mu 1$ of medium. Subsequently, all cells were subjected to $1 \mathrm{~h}$ of incubation under normoxic conditions, washed with $1 \mathrm{ml}$ ice-cold PBS, resuspended in $400 \mu 1$ of flow cytometry buffer (PhiPhiLux) and analyzed for caspase-3 activity by flow 

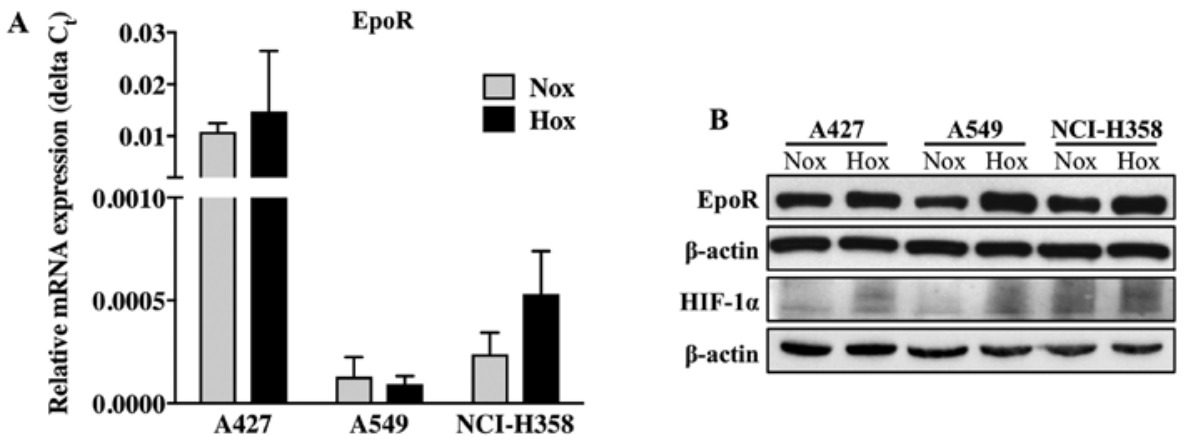

Figure 1. Expression of EpoR in NSCLC cell lines. (A) Relative mRNA expression of EpoR under normoxic (Nox) and hypoxic (Hox) conditions depicted as delta $\mathrm{C}_{\mathrm{T}}$ and $\beta$-actin as the reference gene. (B) Protein expression of EpoR (EpoR $59 \mathrm{kDa}$, $\beta$-actin $42 \mathrm{kDa}$ ) and HIF-1 $\alpha$ (120 kDa) under normoxic (Nox) and hypoxic (Hox) conditions. Data represent the means \pm SD of at least 3 independent experiments. Representative immunoblots are shown.
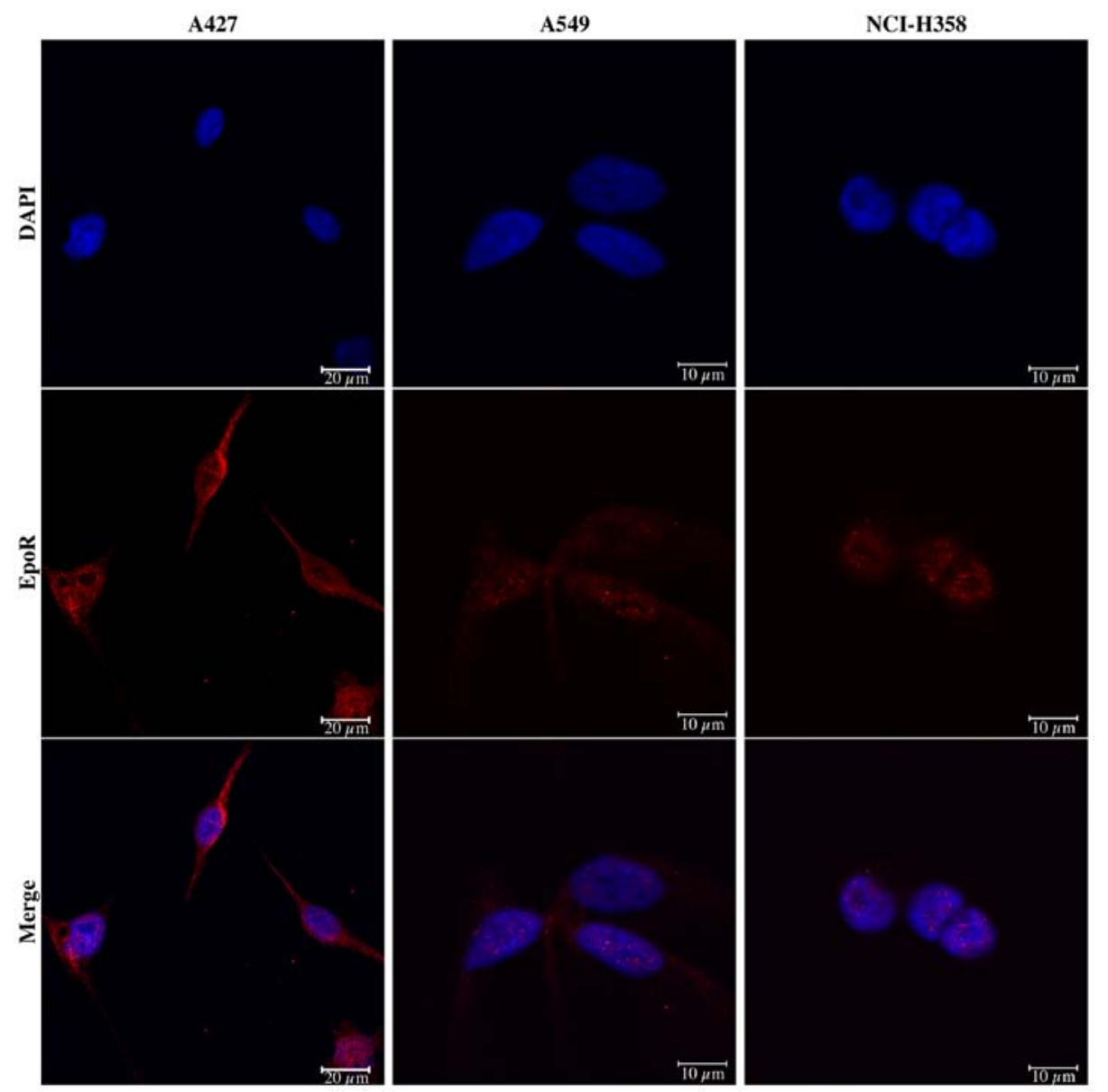

Figure 2. Immunocytochemical staining of EpoR in NSCLC cell lines. EpoR (red dye) in 3 NSCLC cell lines incubated under hypoxic conditions analyzed by confocal laser scanning microscopy. As a negative control, staining was performed in the absence of the primary antibody for A427 cells, or with an isotype IgG as the primary antibody for the A549 and NCI-H358 cells. DAPI, nucleus staining (blue dye).

cytometry (FACSCalibur ${ }^{\circledR}$ flow cytometer; BD Biosciences, San Jose, CA, USA).

Statistical analyses. All experiments were repeated at least 3 times. Data were compiled and analyzed using the software package GraphPad Prism version 5.03 (GraphPad Software, Inc., La Jolla, CA, USA) or SPSS, version 14.0 (IBM SPSS, Chicago, IL, USA). Group differences were calculated using the Student's t-test and two-way analysis of variance (ANOVA) with post hoc analysis (Bonferroni correction). Two-sided
$\mathrm{P}<0.05$ were considered to indicate statistically significant differences. Results are expressed as the means \pm standard deviation (SD).

\section{Results}

Expression of EpoR in NSCLC cell lines. All 3 cell lines expressed EpoR mRNA (Fig. 1A). The EpoR mRNA levels were highest in the A427 cells, both under normoxic and hypoxic conditions. The mRNA level of EpoR did not differ 


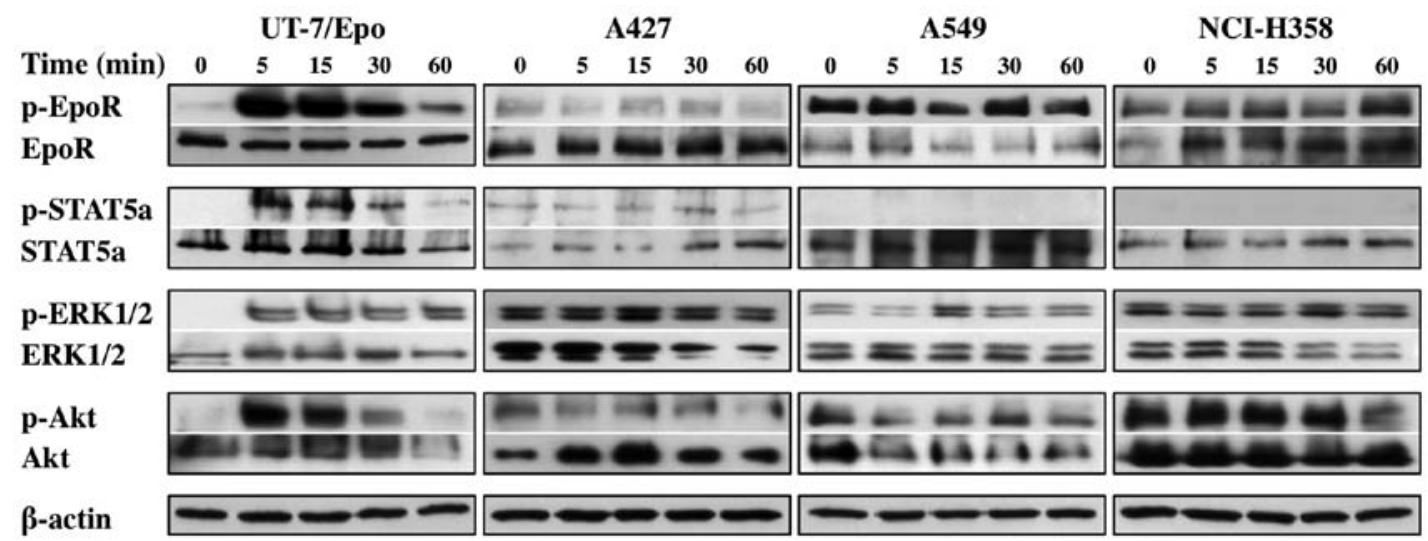

Figure 3. Western blot analyses of EpoR signaling in NSCLC cell lines. Comparison of receptor activation and downstream signaling over $1 \mathrm{~h}$ of stimulation with Epo (100 U/ml). Immunoreactivity was visualized with antibodies against p-EpoR (70 kDa), EpoR (59 kDa), p-STAT5a (90 kDa), STAT5a (92 kDa), p-ERK1/2 and ERK1/2 (42/44 kDa), p-Akt and Akt (60 kDa) and $\beta$-actin $(43 \mathrm{kDa})$. UT-7/Epo cells served as Epo-dependent positive controls that proved the experimental principle. $\beta$-actin served as a loading control. Representative blots of 3 independent experiments are shown.
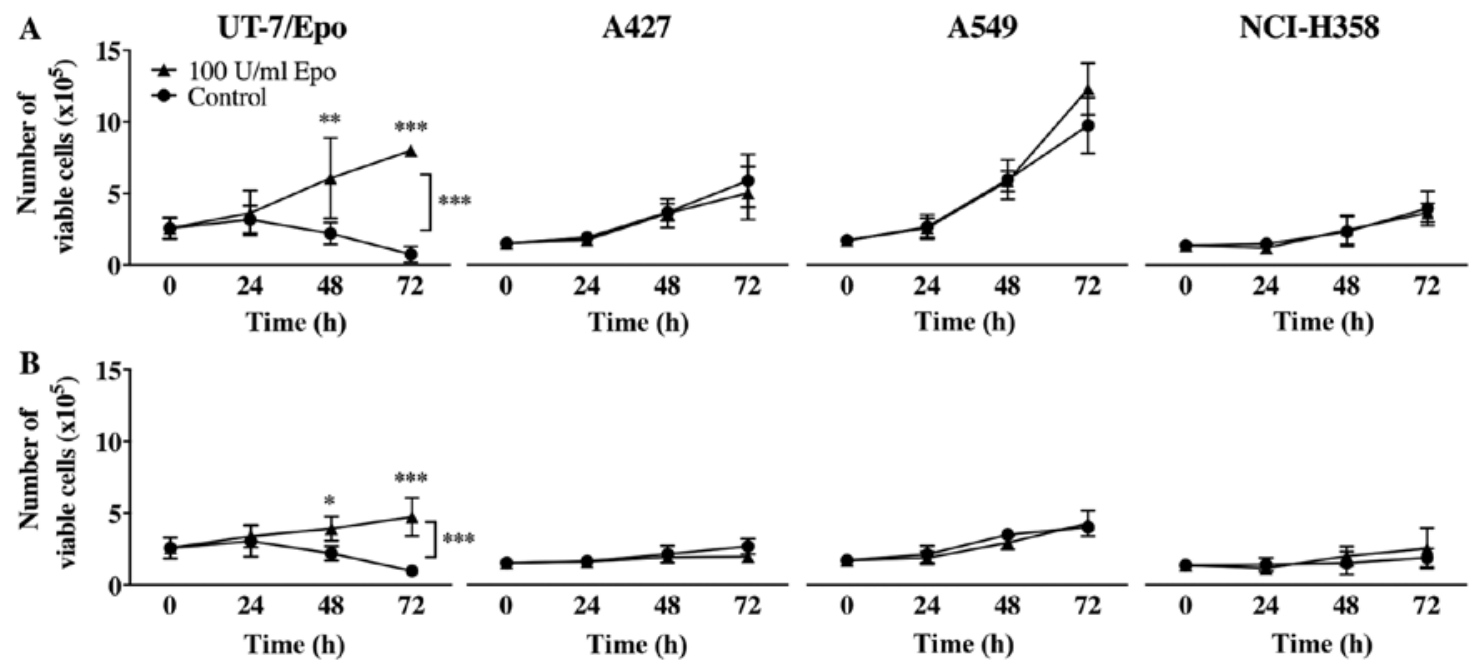

Figure 4. Effects of Epo on NSCLC cell proliferation. The number of viable cells was measured under (A) normoxic and (B) hypoxic conditions for 3 consecutive days. The UT-7/Epo cells served as an Epo-dependent positive control that proved the experimental principle. Statistics were performed using two-way ANOVA with Bonferroni correction $\left({ }^{*} \mathrm{P}<0.05,{ }^{* *} \mathrm{P}<0.01\right.$ and $\left.{ }^{* * *} \mathrm{P}<0.001\right)$. Data represent the means $\pm \mathrm{SD}$ of 3 independent experiments. The legend in panel (A) applies to all diagrams in this figure.

in the cells cultured under normoxic or hypoxic conditions. Western blot analysis of EpoR revealed that EpoR mRNA was translated into the mature, full-length form of EpoR protein $(59 \mathrm{kDa})$ in all $3 \mathrm{NSCLC}$ cell lines (Fig. 1B). Hypoxic conditions were confirmed by immunoblotting for hypoxiainducible factor $1 \alpha$ (HIF-1 $\alpha$ ), one of the most important and well described regulatory proteins in hypoxia (Fig. 1B). As expected, HIF-1 $\alpha$ protein expression was increased under hypoxic conditions, particularly in the A427 and A549 cells, whereas in the NCI-H358 cells, this difference was less prominent. As shown by confocal laser scanning microscopy, all NSCLC cells exhibited immunofluorescence staining for EpoR protein (Fig. 2), which appeared to be most prominent in the A427 cells. The localization of EpoR was mainly cytoplasmic and perinuclear.

Activity and functionality of EpoR in NSCLC cells. Since we found EpoR protein expression in these NSCLC cell lines, we explored its functionality via the analysis of the activating phos- phorylation of EpoR and its downstream signaling pathways. All NSCLC cells exhibited the continuous phosphorylation of EpoR, ERK1/2 and Akt proteins, and the A427 cells also exhibited the phosphorylation of STAT5a protein, which was independent of exogenous Epo administration (Fig. 3). By contrast, the Epo-dependent UT-7/Epo cells exhibited a clear time-dependent activation of EpoR, STAT5a, ERK1/2 and Akt proteins, peaking in intensity after $5 \mathrm{~min}$ and gradually declining within $1 \mathrm{~h}$.

Proliferation of Epo-treated NSCLC cell lines under hypoxic conditions. To examine the effects of Epo on the proliferation of the NSCLC cells, electronic pulse area analysis was conducted to count all 4 cell lines treated with or without Epo $(100 \mathrm{U} / \mathrm{ml})$ both under normoxic and hypoxic conditions for up to $72 \mathrm{~h}$.

Epo did not lead to a statistically significant growth advantage of the A427, A549 and NCI-H358 cells neither under normoxic nor under hypoxic conditions (Fig. 4). The UT-7/Epo 

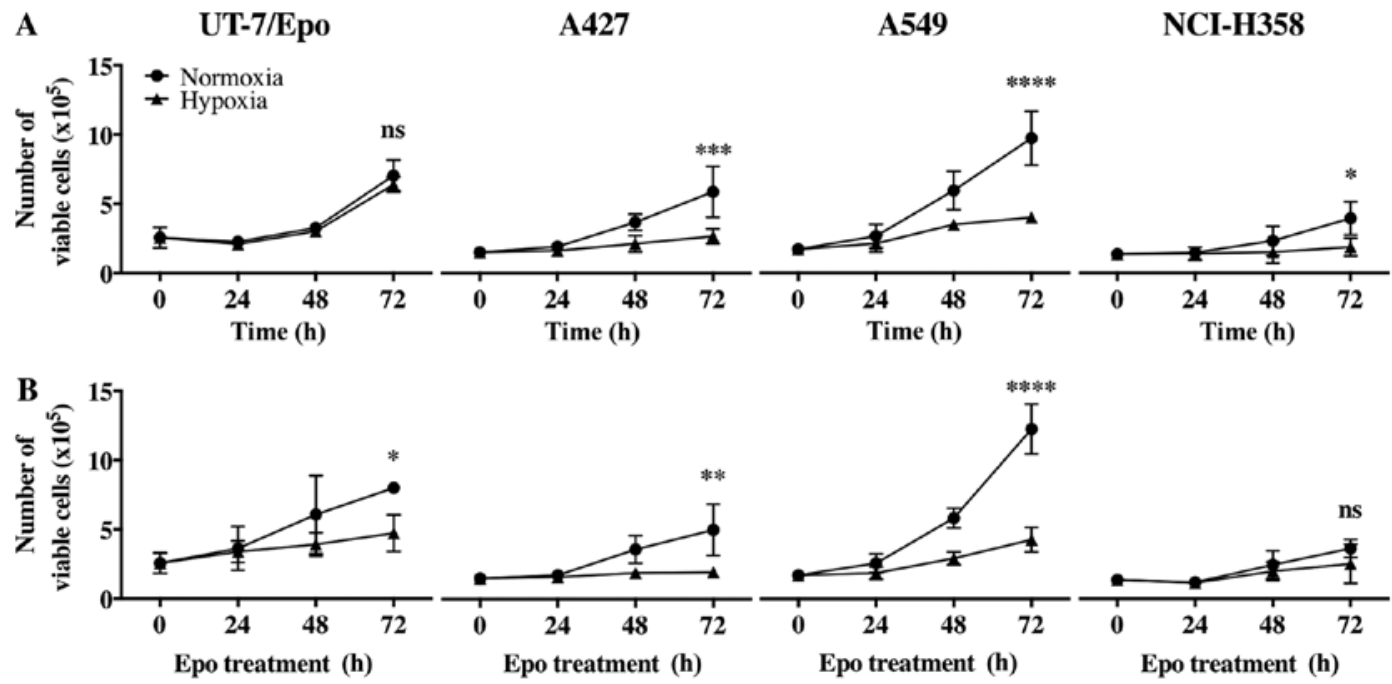

Figure 5. Effects of hypoxia on the proliferation of NSCLC cell lines. (A) NSCLC cell lines were cultured under hypoxic conditions $\left(1 \% \mathrm{O}_{2}\right)$ without Epo stimulation (UT-7/Epo received basal stimulation of $0.4 \mathrm{U} / \mathrm{ml}$ of Epo). (B) NSCLC cell lines under hypoxic conditions with Epo stimulation (100 U/ml). Statistics were performed using a two-way ANOVA with Bonferroni correction (ns, not significant, ${ }^{*} \mathrm{P}<0.05,{ }^{* *} \mathrm{P}<0.01,{ }^{* * * *} \mathrm{P}<0.001$ and ${ }^{* * * * *} \mathrm{P}<0.0001$ ), where the asterisks designate the overall difference within $72 \mathrm{~h}$ of cell culture. Data represent the means \pm SD. The legend in panel (A) applies to all diagrams in this figure.
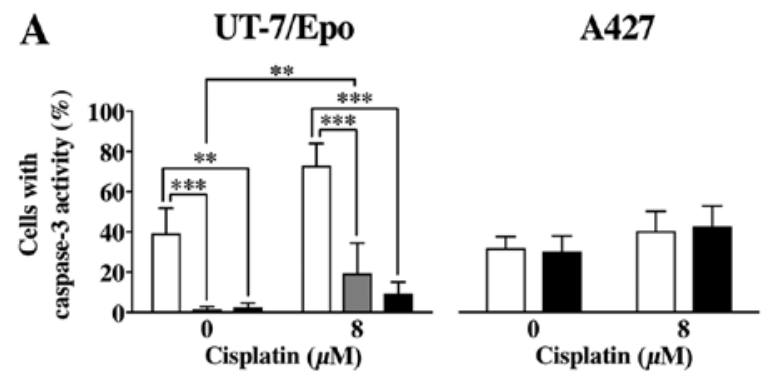

A549
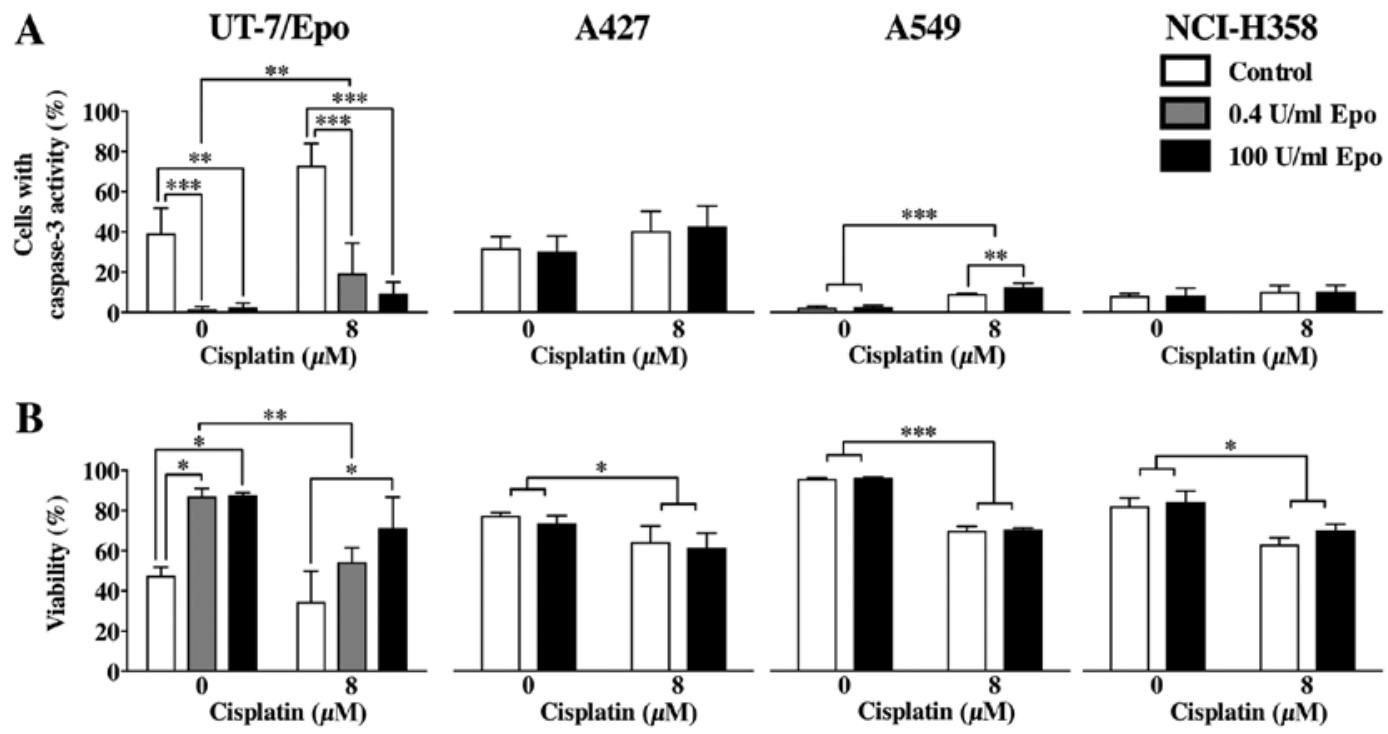

Figure 6. Effects of Epo on caspase-3 activation due to cisplatin in NSCLC cell lines under normoxic conditions. (A) Detection of activated caspase-3 measured by flow cytometry. (B) Detection of cell viability measured by electronic pulse area analysis (CASY). UT-7/Epo cells served as an Epo-dependent positive control that proved the experimental principle. Statistics were performed using a two-way ANOVA with Bonferroni correction $\left({ }^{*} \mathrm{P}<0.05,{ }^{* *} \mathrm{P}<0.01\right.$ and $\left.{ }^{* * * *} \mathrm{P}<0.001\right)$. Data represent the means \pm SD of 3 independent experiments. The legend in panel (A) applies to all diagrams in this figure.

cells, however, exhibited a clear Epo-dependent overall increase in cell number $(\mathrm{P}<0.0001$, two-way ANOVA). In the post hoc subgroup analyses, the number of viable UT-7/Epo cells under normoxic and hypoxic conditions differed significantly after $48 \mathrm{~h}$ of Epo treatment $(\mathrm{P}<0.01$ and $\mathrm{P}<0.05$, respectively). Hypoxia itself led to a statistically significant overall decrease in the number of viable cells without Epo treatment: A427 cells, $\mathrm{P}=0.0008$; A549 cells, $\mathrm{P}<0.0001$; NCI-H358 cells, $\mathrm{P}=0.02$; two-way ANOVA (Fig. 5).

Apoptosis of Epo-treated NSCLC cell lines. To determine the extent of apoptosis by the detection activated caspase-3, all cell lines were analyzed for caspase- 3 activity by flow cytometry. Treatment with $8 \mu \mathrm{M}$ cisplatin led to a significant decrease in the viability of all cell lines, which was independent of Epo treatment (UT-7/Epo cells, $\mathrm{P}<0.01$; A427 cells, $\mathrm{P}<0.05$; A549 cells, $\mathrm{P}<0.0001$; NCI-H358 cells, $\mathrm{P}<0.01$, Fig. 6). An increased number of cells with caspase-3 activity due to cisplatin treatment was only found in the UT-7/Epo and A549 cells $(\mathrm{P}=0.001$ and $\mathrm{P}<0.0001$, respectively), but not in the A427 and NCI-H358 cells $(\mathrm{P}=0.0636$ and $\mathrm{P}=0.2433$, respectively). Epo did not lead to a significant reduction in the number of cells with caspase-3 activity in the A427, A549 and NCI-H358 cells, which was independent of cisplatin treatment, in contrast to the UT-7/Epo cells (0.4 and $100 \mathrm{U} / \mathrm{ml}$ Epo, overall effect of Epo, $\mathrm{P}<0.0001)$. An analysis of cell viability revealed that cisplatin treatment induced a significant reduction in the number of viable cells in all cell lines (Fig. 6B). Epo treatment did not reverse this 
cytotoxic effect of cisplatin in the NSCLC cell lines in contrast to the UT-7/Epo cell line, in which Epo reversed the effects of cisplatin.

\section{Discussion}

Recombinant human Epo is an effective treatment option for chemotherapy-induced anemia in lung cancer patients. Results from clinical trials have suggested that adverse effects, including a higher mortality rate are due to the use of Epo (12), and have prompted concerns as to the safety of Epo, and thus its molecular effects on tumor cells $(7,14)$. Results from cell-based analyses that have investigated the presence and functionality of EpoR in tumor cells, as well as the effects of its ligand Epo have been largely contradictory $(33,34)$.

The present in vitro study aimed to assess the expression and the functionality of EpoR in selected NSCLC cell lines, as well as the effects of Epo on cell proliferation and apoptosis under normoxic and hypoxic conditions. We found that the NSCLC cell lines A427, A549 and NCI-H358 expressed EpoR mRNA and protein. Immunocytochemical staining of the receptor protein identified a mainly cytoplasmic and perinuclear localization. Epo did not lead to a ligand-dependent activation of neither EpoR nor further downstream signaling pathways (STAT5, PI3K-Akt and ERK1/2). EpoR appeared to be rather constitutively active. While Epo markedly enhanced the proliferation and reduced the apoptosis of Epo-dependent UT-7/Epo leukemia cells, it did not affect the proliferation or the cisplatin-induced apoptosis of NSCLC cells.

Intratumoral hypoxia is known for its ambivalent effects leading on one hand to restrained proliferation, differentiation, apoptosis and necrosis. On the other had, it may indeed result in a more aggressive tumor phenotype, tumor progression and acquired resistance $(26,35)$. In this study, to mimic lower oxygen levels that commonly exist in lung tumors in vivo, we cultured the NSCLC cell lines in all hypoxic experiments at $1 \% \mathrm{O}_{2}$. Hypoxic conditions were confirmed by immunoblotting for HIF-1 $\alpha$ in all 3 NSCLC cell lines. The A427, A549 and NCI-H358 cells exhibited a statistically significant decrease in cell growth due to hypoxia. We did not detect an altered transcription of either EpoR mRNA or its protein due to hypoxia.

The presence of EpoR in the selected NSCLC cell lines makes them potentially able to respond to an appropriate stimulation with Epo. The NSCLC cells showed in confocal laser scanning microscopy a mainly cytoplasmic and perinuclear fluorescent signal of EpoR protein, raising the question of how EpoR can be reached and activated by its ligand. However, the predominant cytoplasmic localization of EpoR is well known for both hematopoietic progenitor and cancer cells $(34,36)$. It has been reported that $<10 \%$ of total EpoR protein is expressed on the cell surface of these cells due to highly dynamic intracellular receptor pools, an incomplete processing in organelles, and a short half-life of EpoR protein $(37,38)$. There are still serious concerns as to the specificity of anti-EpoR antibodies commonly used in recent studies on non-hematopoietic and in particular malignant cells $(33,39)$. Nevertheless, the anti-EpoR antibody applied in this study (M-20, Santa Cruz Biotechnology) has been described to be suitable for the detection of EpoR with immunoblots (33). This antibody was able to differentiate Epo-stimulated from unstimulated EpoR in the positive control UT-7/Epo cells and to detect the full-length form of EpoR at $59 \mathrm{kDa}$ with immunoblots.

Apart from the expression of EpoR, its functionality seems to be another crucial factor that may be responsible for the influence of Epo on cancer cell progression $(34,40)$. Some studies have provided evidence that EpoR is capable of transmitting the Epo-driven signal into the cell via cascades of activating protein phosphorylation in selected cancer cells $(17,23,41-43)$. Others have shown that a range of cancer cell lines does not express a functionally active EpoR (34). In this study, we demonstrated that EpoR expression was present in all 3 NSCLC cell lines and was rather constitutively phosphorylated, which was also independent of exogenous Epo administration. Likewise, the signaling pathways downstream of EpoR appeared to be continuously activated in these lung cancer cells, even though these cells had been cultured in serum-free starvation medium prior to and during the Epo challenge to reduce disturbing and unspecific signaling. A constitutive activation of EpoR and its downstream signaling pathways may reduce the sensitivity of these cells towards growth factor stimulation, such as Epo. A certain intracellular cross-activation of these signaling pathways may also explain the downstream phosphorylation. However, the control cell line, UT-7/Epo, underwent identical treatment and displayed no baseline phosphorylation of any of the downstream pathways tested. The possibility that EpoR can be constitutively phosphorylated and thus activated has already been described, e.g., in human ovarian carcinoma cells (44). All 3 NSCLC cell lines exhibited an activating point mutation in codon 12 of the KRAS gene, leading to an enhanced activation of the MAP kinase pathway and thus enhanced proliferation $(45,46)$. It is conceivable that the effect of Epo may not be registered due to constitutively active KRAS protein. Likewise, the time-course experiments showed phosphorylation of ERK1/2 without Epo stimulation in all cell lines, although they were cultured in starvation medium. The crosstalk between these signaling pathways (Jak2-STAT5, PI3K-Akt and MAP kinase) may explain a protein phosphorylation in unstimulated cells.

In our experimental model, $100 \mathrm{U} / \mathrm{ml}$ of Epo did not significantly stimulate the proliferation of the NSCLC cells nor did it protect them from apoptosis. According to other authors (9), we consider this concentration as suprapharmacologic compared with physiological basal plasma concentrations of Epo ranging from 6 to $32 \mathrm{U} / 1$ (25). The results from the proliferation and apoptosis experiments on the protective effects of Epo in tumor cells are, by now, rather contradictory. Some studies have shown that Epo has the capacity to enhance cancer cell progression in diverse cancer cell types $(16,17,47-49)$, while others have demonstrated the opposite $(23,40,50-57)$.

Since EpoR appeared to be constitutively phosphorylated in these 3 lung cancer cell lines, the anti-apoptotic and proliferative effects of exogenous Epo may not be sufficiently determinable. Nevertheless, the control cell line, UT-7/Epo, confirmed the principle of the design of this study and responded to Epo treatment in a clear Epo-dependent manner, increasing proliferation and reducing apoptosis.

We also assessed the cytotoxic effects of cisplatin via the induction of apoptosis (caspase-3 activation) and cell 
viability. The latter was derived from the proportion of viable cells, which was calculated in function of the cell volume and assessed by electronic pulse area analysis. Based on our previous studies $(26,58)$, we know that higher cisplatin concentrations induce the prominent and rapid apoptosis of NSCLC cell lines. We intended to induce apoptosis and cell death in general with a cisplatin concentration $(8 \mu \mathrm{M})$ that is low enough to allow a sufficient amount of viable cells to remain, which are still able to respond to exogenous Epo. This cisplatin concentration is similar to values measured in the serum of patients treated with cisplatin, and is thus clinically relevant. This concentration was able to induce the irreversible apoptosis of the A549, but not that of the A427 and NCI-H358 cells. However, the viability of all these cell lines was significantly reduced by treatment with $8 \mu \mathrm{M}$ of cisplatin. Therefore, we can conclude that the cytotoxic effects of cisplatin in the given concentration were sufficiently high to universally reduce cell viability, but not to induce significant apoptosis in all cell lines. This may be due to the different susceptibilities to cisplatin of each cell line.

As a limitation of our study, the results derived from isolated cancer cells and the nature of this study excluded the investigation of any molecular interplay between the tumor cells and the surrounding tumor microenvironment, i.e., stromal cells such as fibroblasts, endothelial or immune cells.

Future experiments are required to focus on the interplay between stromal and NSCLC cells. For instance, a simple co-culture system of these cell types would allow the assessment of the effects of Epo between them in terms of cancer cell survival and proliferation. Furthermore, a novel and appealing strategy may be tumor-derived organotypic slice cultures, in which the effects of both chemotherapeutics and Epo can be analyzed (59-61). In contrast to pure monoculture experiments, this model allows a partial preservation of the human tumor microenvironment, the collection of samples from the media over time, the analysis of the effect of cytotoxic drugs, and thus, a possible prediction of tumor response or resistance to therapy (59).

In conclusion, in our experimental setting, exogenous Epo had no significant effect on the proliferation and apoptosis of NSCLC cell lines, neither under hypoxic nor under normoxic conditions despite the expression of EpoR.

\section{Acknowledgements}

We are grateful to Dr Zoltán Bálint (Ludwig Boltzmann Institute for Lung Vascular Research) for the preparation of the confocal imaging, and to Elisabeth Pöllitzer, BSc and Alexandra Bertsch, MSc (Division of Pulmonology, Department of Internal Medicine, Medical University of Graz) for their excellent technical assistance. In addition, we would like to thank Dr Slaven Crnkovic and all other members of the Ludwig Boltzmann Institute for Lung Vascular Research, Graz, Austria, as well as the core-facilities at the Center for Medical Research (Zentrum für Medizinische Grundlagenforschung, ZMF) at the Medical University of Graz for their support. Furthermore, we are very grateful for the generosity of Professor Dr Norio Komatsu (Department of Hematology, Juntendo University, Tokyo, Japan) for providing the control cell line UT-7/Epo. Dr Armin Frille was temporarily supported by the Federal Ministry of Education and Research (BMBF), Germany, FKZ: 01EO1501 (IFB AdiposityDiseases, MetaRot program).

\section{References}

1. Torre LA, Bray F, Siegel RL, Ferlay J, Lortet-Tieulent J and Jemal A: Global cancer statistics, 2012. CA Cancer J Clin 65: 87-108, 2015

2. Reck M, Popat S, Reinmuth N, De Ruysscher D, Kerr KM and Peters S; ESMO Guidelines Working Group: Metastatic non-small-cell lung cancer (NSCLC): ESMO Clinical Practice Guidelines for diagnosis, treatment and follow-up. Ann Oncol 25 (Suppl 3): iii27-iii39, 2014.

3. Pirker R, Wiesenberger K, Pohl G and Minar W: Anemia in lung cancer: Clinical impact and management. Clin Lung Cancer 5: 90-97, 2003.

4. Caro JJ, Salas M, Ward A and Goss G: Anemia as an independent prognostic factor for survival in patients with cancer: A systemic, quantitative review. Cancer 91: 2214-2221, 2001.

5. Gilreath JA, Stenehjem DD and Rodgers GM: Diagnosis and treatment of cancer-related anemia. Am J Hematol 89: 203-212, 2014.

6. Crawford J, Demetri GD, Gabrilove JL, Blasi MV, Sarokhan BJ and Glaspy J: Clinical benefits of epoetin alfa therapy in patients with lung cancer. Clin Lung Cancer 3: 180-190, 2002.

7. Rizzo JD, Brouwers M, Hurley P, Seidenfeld J, Arcasoy MO, Spivak JL, Bennett CL, Bohlius J, Evanchuk D, Goode MJ, et al; American Society of Hematology and the American Society of Clinical Oncology Practice Guideline Update Committee: American Society of Hematology/American Society of Clinical Oncology clinical practice guideline update on the use of epoetin and darbepoetin in adult patients with cancer. Blood 116: 4045-4059, 2010.

8. Jelkmann W, Bohlius J, Hallek M and Sytkowski AJ: The erythropoietin receptor in normal and cancer tissues. Crit Rev Oncol Hematol 67: 39-61, 2008.

9. Sinclair AM, Todd MD, Forsythe K, Knox SJ, Elliott S and Begley CG: Expression and function of erythropoietin receptors in tumors: Implications for the use of erythropoiesis-stimulating agents in cancer patients. Cancer 110: 477-488, 2007.

10. Szenajch J, Wcislo G, Jeong JY, Szczylik C and Feldman L: The role of erythropoietin and its receptor in growth, survival and therapeutic response of human tumor cells: From clinic to bench - a critical review. Biochim Biophys Acta 1806: 82-95, 2010.

11. Wright JR, Ung YC, Julian JA, Pritchard KI, Whelan TJ, Smith C, Szechtman B, Roa W, Mulroy L, Rudinskas L, et al: Randomized, double-blind, placebo-controlled trial of erythropoietin in nonsmall-cell lung cancer with disease-related anemia. J Clin Oncol 25: 1027-1032, 2007.

12. Bohlius J, Schmidlin K, Brillant C, Schwarzer G, Trelle S, Seidenfeld J, Zwahlen M, Clarke M, Weingart O, Kluge S, et al: Recombinant human erythropoiesis-stimulating agents and mortality in patients with cancer: A meta-analysis of randomised trials. Lancet 373: 1532-1542, 2009.

13. Rizzo JD, Somerfield MR, Hagerty KL, Seidenfeld J, Bohlius J, Bennett CL, Cella DF, Djulbegovic B, Goode MJ, Jakubowski AA, et al: Use of epoetin and darbepoetin in patients with cancer: 2007 American Society of Hematology/American Society of Clinical Oncology clinical practice guideline update. Blood 111: 25-41, 2008.

14. Rodgers GM III, Becker PS, Blinder M, Cella D, ChananKhan A, Cleeland C, Coccia PF, Djulbegovic B, Gilreath JA, Kraut EH, et al: Cancer- and chemotherapy-induced anemia (Version 1.2018). J Natl Compr Canc Netw 10: 628-653, 2017

15. Osterborg A, Aapro M, Cornes P, Haselbeck A, Hayward CR and Jelkmann W: Preclinical studies of erythropoietin receptor expression in tumour cells: Impact on clinical use of erythropoietic proteins to correct cancer-related anaemia. Eur J Cancer 43: 510-519, 2007.

16. Westenfelder C and Baranowski RL: Erythropoietin stimulates proliferation of human renal carcinoma cells. Kidney Int 58: 647-657, 2000.

17. Feldman L, Wang Y, Rhim JS, Bhattacharya N, Loda M and Sytkowski AJ: Erythropoietin stimulates growth and STAT5 phosphorylation in human prostate epithelial and prostate cancer cells. Prostate 66: 135-145, 2006 
18. Acs G, Chen M, Xu X, Acs P, Verma A and Koch CJ: Autocrine erythropoietin signaling inhibits hypoxia-induced apoptosis in human breast carcinoma cells. Cancer Lett 214: 243-251, 2004.

19. Dolznig H, Habermann B, Stangl K, Deiner EM, Moriggl R, Beug $\mathrm{H}$ and Müllner EW: Apoptosis protection by the Epo target $\mathrm{Bcl}-\mathrm{X}_{\mathrm{L}}$ allows factor-independent differentiation of primary erythroblasts. Curr Biol 12: 1076-1085, 2002.

20. Hardee ME, Cao Y, Fu P, Jiang X, Zhao Y, Rabbani ZN, Vujaskovic Z, Dewhirst MW and Arcasoy MO: Erythropoietin blockade inhibits the induction of tumor angiogenesis and progression. PLoS One 2: e549, 2007.

21. Batra S, Perelman N, Luck LR, Shimada H and Malik P: Pediatric tumor cells express erythropoietin and a functional erythropoietin receptor that promotes angiogenesis and tumor cell survival. Lab Invest 83: 1477-1487, 2003.

22. Dagnon K, Pacary E, Commo F, Antoine M, Bernaudin M, Bernaudin JF and Callard P: Expression of erythropoietin and erythropoietin receptor in non-small cell lung carcinomas. Clin Cancer Res 11: 993-999, 2005.

23. Dunlop EA, Percy MJ, Boland MP, Maxwell AP and Lappin TR Induction of signalling in non-erythroid cells by pharmacological levels of erythropoietin. Neurodegener Dis 3: 94-100, 2006.

24. Vaupel P and Harrison L: Tumor hypoxia: Causative factors, compensatory mechanisms, and cellular response. Oncologist 9 (Suppl 5): 4-9, 2004

25. Jelkmann W: Regulation of erythropoietin production. J Physiol 589: 1251-1258, 2011

26. Wohlkoenig C, Leithner K, Deutsch A,Hrzenjak A, Olschewski A and Olschewski $\mathrm{H}$ : Hypoxia-induced cisplatin resistance is reversible and growth rate independent in lung cancer cells. Cancer Lett 308: 134-143, 2011.

27. Komatsu N, Yamamoto M, Fujita H, Miwa A, Hatake K, Endo T, Okano H, Katsube T, Fukumaki Y, Sassa S, et al: Establishment and characterization of an erythropoietin-dependent subline, UT-7/Epo, derived from human leukemia cell line, UT-7. Blood 82: 456-464, 1993.

28. Erickson-Miller CL, Pelus LM and Lord KA: Signaling induced by erythropoietin and stem cell factor in UT-7/Epo cells: Transient versus sustained proliferation. Stem Cells 18: 366-373, 2000.

29. Schmittgen TD and Livak KJ: Analyzing real-time PCR data by the comparative C(T) method. Nat Protoc 3: 1101-1108, 2008.

30. Belenkov AI, Shenouda G, Rizhevskaya E, Cournoyer D, Belzile JP, Souhami L, Devic S and Chow TY: Erythropoietin induces cancer cell resistance to ionizing radiation and to cisplatin. Mol Cancer Ther 3: 1525-1532, 2004.

31. Gormley PE, Bull JM, LeRoy AF and Cysyk R: Kinetics of cisdichlorodiammineplatinum. Clin Pharmacol Ther 25: 351-357, 1979.

32. Himmelstein KJ, Patton TF, Belt RJ, Taylor S, Repta AJ and Sternson LA: Clinical kinetics on intact cisplatin and some related species. Clin Pharmacol Ther 29: 658-664, 1981

33. Elliott S, Busse L, Bass MB, Lu H, Sarosi I, Sinclair AM, Spahr C, Um M, Van G and Begley CG: Anti-Epo receptor antibodies do not predict Epo receptor expression. Blood 107: 1892-1895, 2006

34. Swift S, Ellison AR, Kassner P, McCaffery I, Rossi J, Sinclair AM, Begley CG and Elliott S: Absence of functional EpoR expression in human tumor cell lines. Blood 115: 4254-4263, 2010.

35. Vaupel P: Hypoxia and aggressive tumor phenotype: Implications for therapy and prognosis. Oncologist 13 (Suppl 3): 21-26, 2008.

36. Hadland BK and Longmore GD: Erythroid-stimulating agents in cancer therapy: Potential dangers and biologic mechanisms. J Clin Oncol 27: 4217-4226, 2009.

37. Neumann D, Wikström L, Watowich SS and Lodish HF: Intermediates in degradation of the erythropoietin receptor accumulate and are degraded in lysosomes. J Biol Chem 268: 13639-13649, 1993.

38. Becker V, Schilling M, Bachmann J, Baumann U, Raue A, Maiwald T, Timmer $\mathbf{J}$ and Klingmüller U: Covering a broad dynamic range: Information processing at the erythropoietin receptor. Science 328: 1404-1408, 2010

39. Brown WM, Maxwell P, Graham AN, Yakkundi A, Dunlop EA, Shi Z, Johnston PG and Lappin TR: Erythropoietin receptor expression in non-small cell lung carcinoma: A question of antibody specificity. Stem Cells 25: 718-722, 2007.

40. Westphal G, Niederberger E, Blum C, Wollman Y, Knoch TA, Rebel W, Debus J and Friedrich E: Erythropoietin and G-CSF receptors in human tumor cells: Expression and aspects regarding functionality. Tumori 88: 150-159, 2002.
41. Kumar SM, Yu H, Fong D, Acs G and Xu X: Erythropoietin activates the phosphoinositide 3-kinase/Akt pathway in human melanoma cells. Melanoma Res 16: 275-283, 2006.

42. Lester RD, Jo M, Campana WM and Gonias SL: Erythropoietin promotes MCF-7 breast cancer cell migration by an ERK/ mitogen-activated protein kinase-dependent pathway and is primarily responsible for the increase in migration observed in hypoxia. J Biol Chem 280: 39273-39277, 2005.

43. Yasuda Y, Fujita Y, Matsuo T, Koinuma S, Hara S, Tazaki A, Onozaki M, Hashimoto M, Musha T, Ogawa K, et al: Erythropoietin regulates tumour growth of human malignancies. Carcinogenesis 24: 1021-1029, 2003.

44. Paragh G, Kumar SM, Rakosy Z, Choi SC, Xu X and Acs G: RNA interference-mediated inhibition of erythropoietin receptor expression suppresses tumor growth and invasiveness in A2780 human ovarian carcinoma cells. Am J Pathol 174: 1504-1514, 2009.

45. Yoon YK, Kim HP, Han SW, Oh DY, Im SA, Bang YJ and Kim TY: KRAS mutant lung cancer cells are differentially responsive to MEK inhibitor due to AKT or STAT3 activation: Implication for combinatorial approach. Mol Carcinog 49: 353-362, 2010.

46. Valenzuela DM and Groffen J: Four human carcinoma cell lines with novel mutations in position 12 of c-K-ras oncogene. Nucleic Acids Res 14: 843-852, 1986.

47. Acs G, Zhang PJ, McGrath CM, Acs P, McBroom J, Mohyeldin A, Liu S, Lu H and Verma A: Hypoxia-inducible erythropoietin signaling in squamous dysplasia and squamous cell carcinoma of the uterine cervix and its potential role in cervical carcinogenesis and tumor progression. Am J Pathol 162: 1789-1806, 2003.

48. Pajonk F, Weil A, Sommer A, Suwinski R and Henke M: The erythropoietin-receptor pathway modulates survival of cancer cells. Oncogene 23: 8987-8991, 2004.

49. Hardee ME, Arcasoy MO, Blackwell KL, Kirkpatrick JP and Dewhirst MW: Erythropoietin biology in cancer. Clin Cancer Res 12: 332-339, 2006.

50. Berdel WE, Danhauser-Riedl S, Oberberg D and Zafferani M: Effects of hematopoietic growth factors on malignant nonhematopoietic cells. Semin Oncol 19 (Suppl 4): 41-45, 1992.

51. Berdel WE, Oberberg D, Reufi B and Thiel E: Studies on the role of recombinant human erythropoietin in the growth regulation of human nonhematopoietic tumor cells in vitro. Ann Hematol 63: $5-8,1991$.

52. Liu WM, Powles T, Shamash J, Propper D, Oliver T and Joel S: Effect of haemopoietic growth factors on cancer cell lines and their role in chemosensitivity. Oncogene 23: 981-990, 2004.

53. Mundt D, Berger MR and Bode G: Effect of recombinant human erythropoietin on the growth of human tumor cell lines in vitro. Micro-titertec-tetrazolium assay. Arzneimittelforschung 42: 92-95, 1992.

54. Rosti V, Pedrazzoli P, Ponchio L, Zibera C, Novella A, Lucotti C, Della Cuna GR and Cazzola M: Effect of recombinant human erythropoietin on hematopoietic and non-hematopoietic malignant cell growth in vitro. Haematologica 78: 208-212, 1993.

55. Rössler J, Stolze I, Frede S, Freitag P, Schweigerer L, Havers W and Fandrey J: Hypoxia-induced erythropoietin expression in human neuroblastoma requires a methylation free HIF-1 binding site. J Cell Biochem 93: 153-161, 2004.

56. Gewirtz DA, Di X, Walker TD and Sawyer ST: Erythropoietin fails to interfere with the antiproliferative and cytotoxic effects of antitumor drugs. Clin Cancer Res 12: 2232-2238, 2006.

57. Rosti V, Pedrazzoli P, Ponchio L, Zibera C, Novella A, Lucotti C, Della Cuna GR and Cazzola M: Effect of recombinant human erythropoietin on hematopoietic and non-hematopoietic malignant cell growth in vitro. Haematologica 78: 208-212, 1993.

58. Fischer C, Leithner K, Wohlkoenig C, Quehenberger F, Bertsch A, Olschewski A, Olschewski $\mathrm{H}$ and Hrzenjak A: Panobinostat reduces hypoxia-induced cisplatin resistance of non-small cell lung carcinoma cells via HIF-1 $\alpha$ destabilization. Mol Cancer 14: 4, 2015.

59. Gerlach MM, Merz F, Wichmann G, Kubick C, Wittekind C, Lordick F, Dietz A and Bechmann I: Slice cultures from head and neck squamous cell carcinoma: A novel test system for drug susceptibility and mechanisms of resistance. Br J Cancer 110: 479-488, 2014.

60. Koerfer J, Kallendrusch S, Merz F, Wittekind C, Kubick C, Kassahun WT, Schumacher G, Moebius C, Gaßler N, Schopow N, et al: Organotypic slice cultures of human gastric and esophagogastric junction cancer. Cancer Med 5: 1444-1453, 2016.

61. Merz L, Höbel S, Kallendrusch S, Ewe A, Bechmann I, Franke H, Merz F and Aigner A: Tumor tissue slice cultures as a platform for analyzing tissue-penetration and biological activities of nanoparticles. Eur J Pharm Biopharm 112: 45-50, 2017. 